\title{
OS MEIOS DE COMUNICAÇÃO COMO PARADIGMA CONSTITUCIONAL DEMOCRÁTICO NO PROCESSO COMUNICATIVO SOCIAL
}

\author{
Felipe da Veiga Dias ${ }^{1}$ \\ Jorge Renato dos Reis ${ }^{2}$
}

\section{RESUMO}

O estudo em comento, a partir de uma visão constitucional, tem como base a visão conjugada entre necessidade informativa-comunicativa para 0 processo democrático, com enfoque na atuação dos meios de comunicação, haja vista que estes são relevantes prestadores de informações na sociedade moderna. A atuação destes se dá por entes privados, porém exercendo uma função pública, visto que auxilia na efetivação de direitos fundamentais e é imprescindível ao processo comunicativo democrático. O artigo apresenta como questionamento se a ação de monopólios informativos nas atividades dos meios de comunicação é capaz de viciar o exercício comunicativo do cidadão, já que a veracidade é componente ético profissional e ao mesmo tempo inerente às ações comunicativas, sendo que nestes casos a verdade pode ser "condicionada" por interesses particulares. Objetivando responder à problemática, estruturou-se a construção a partir da importância da linguagem, base hermenêutica, e do pensamento comunicativo de Habermas, podendo-se com isso conectá-lo à atividade dos meios de comunicação, aos direitos fundamentais e à visão de democracia, com base no agir comunicativo, para ao final aludir o caráter negativo da influência dos monopólios destes entes privados nas ações da sociedade, tendo em vista a possibilidade de vício da verdade, consequentemente do processo comunicativo e democrático, por parte de interesses individuais.

Palavras-chave: Constituição. Democracia. Entes privados. Meios de comunicação. Serviço público.

\section{INTRODUÇÃO}

A realidade global hodierna aduz a necessidade informativa da sociedade, e esta não se dá somente pelos anseios de consumo de conhecimento, como forma de mercadoria (sociedade da informação), mas também como componente essencial a qualquer processo dialogal entre indivíduos, ou seja, não basta apenas debater, pois tal relação requer um mínimo conhecimento para fundamentação da conversação. O significado da sentença supra não tem o condão apenas da correlação cotidiana entre pessoas, e sim de delinear os traços comunicativos forçosos à estruturação democrática, característica do próprio modelo estatal (Estado Democrático de Direito).

Com base na visão combinada entre necessidade informativacomunicativa para o processo democrático tem-se o enfoque dos meios de comunicação, estes atuando como prestadores de informações, por parte da 
iniciativa privada, porém entendendo-se ser tal atividade um serviço público, visto que auxilia na efetivação de direitos fundamentais e é imprescindível ao processo comunicativo democrático.

Dessa forma o artigo em tela apresenta como questionamento se a ação de monopólios informativos nas atividades dos meios de comunicação é capaz de viciar o exercício comunicativo do cidadão, haja vista que a veracidade é componente ético profissional e ao mesmo tempo inerente às ações comunicativas, sendo que nestes casos a verdade pode ser "condicionada" por interesses particulares (ação estratégica).

A fim de responder à problemática proposta, estruturar-se-á uma construção a partir da importância da linguagem e do pensamento comunicativo de Habermas, podendo-se com isso conectá-lo à atividade dos meios de comunicação, aos direitos fundamentais e à visão de democracia, com base no agir comunicativo, para ao final apresentar posicionamento sobre a influência (ou não) dos monopólios destes entes privados nas ações da sociedade contemporânea.

\section{BREVES NOÇÕES ACERCA DA IMPORTÂNCIA DA LINGUAGEM: O AGIR COMUNICATIVO E A HERMENÊUTICA CONTEMPORÂNEA}

A relevância da linguagem no estudo jurídico-filosófico é relativamente recente, tal afirmação encontra guarida na observação histórica, já que no período estatal liberal, amparado pelo positivismo jurídico, esse aspecto do processo interpretativo era subjugado a uma posição de inferioridade, tão somente como mecanismo ${ }^{3}$. Adotando a visão formal-metodológica ao processo hermenêutico, diversas escolas oportunizaram enfoques nessa época, todas no mesmo sentido, restando o papel de coadjuvante à linguagem ${ }^{4}$.

No entanto, após o declínio da ótica positivista associada à superação da visão jusnaturalista, a linguagem e o intérprete ganham novo gás no mundo jurídico; estes acontecimentos são nutridos pela renovação axiológica ocorrida no período pós-guerra (pós-positivismo) ${ }^{5}$, visando consolidar um pensamento mais humano e flexível, distanciando-se do modelo positivista que, seja por opção metodológica ou não ${ }^{6}$, deixou margem para legitimidade de ofensas múltiplas ao ser humano, por meio dos regimes totalitários.

A nova etapa para o uso da linguagem e, consequentemente, da hermenêutica, teve importantes pensadores; dentre esses filósofos tem-se Heidegger e Gadamer, os quais contribuíram para elevação do valor da linguagem e da própria interpretação com 0 chamado giro linguístico ontológico ${ }^{7}$. Este último caracteriza-se da seguinte forma: todo indivíduo detém uma pré-compreensão decorrente de sua historicidade, todavia, ele somente alcança a compreensão através do processo interpretativo, o qual esclarece o conhecimento intelectivo inicial (pré-compreensão) ${ }^{8}$. 
Heidegger põe em evidência a linguagem como forma de acessar o mundo e os objetos que dele fazem parte ${ }^{9}$. Com isso o autor acaba por relativizar a questão da verdade com base no aspecto temporal (finitude), esta tão determinante para determinados juristas, marcados pelo estigma positivista. Ainda, afirma Heidegger que o processo interpretativo tem por dever a manutenção de cientificidade, não cedendo a meras intuições.

Ademais, contribui Gadamer ao pensamento supramencionado, ao extinguir a dicotomia sujeito-objeto, estabelecendo-a como uma relação préexistente, abandonando a visão da linguagem como terceiro elemento interposto entre o primeiro elemento (sujeito) e o segundo (objeto). Explicam bem o pensamento de Gadamer, acerca da importância da linguagem, as palavras de Manfredo Araújo de Oliveira ao dizer que "toda compreensão é interpretação, e toda interpretação se desenvolve no seio da linguagem, que quer deixar o objeto vir à palavra e, ao mesmo tempo, é a linguagem própria ao intérprete" 10 .

Em breve parêntese situa-se aqui tais fundamentos filosóficos como a base teórica que sustenta a moderna interpretação jurídica, ou seja, deixando de lado visões que desejavam auferir a vontade da norma ou que entendiam ser o Direito um conjunto de normas pré-concebidas em seu conteúdo ${ }^{11}$, para prosseguir ao estabelecimento conjunto de interpretações e consolidações do pensamento jus-reflexivo.

Prosseguindo na análise sobre a importância da linguagem, embora evidente do ponto de vista hermenêutico-jurídico atual, retoma-se aqui um enfoque pautado nos ideais gadamerianos, tendo em vista a sua contribuição com pensamentos valiosos sobre a transmissão da pré-compreensão (tradição) e a conversação para realização da linguagem ${ }^{12}$. Este último elemento será aqui tomado como elo de conexão entre o pensamento hermenêutico e a visão de Habermas sobre a relevância da linguagem e do processo comunicativo para formação da compreensão humana, já que em ambas as linhas de raciocínio há preocupação com a conversação ou debate para o processo de conhecimento.

Entretanto, antes de dar seguimento, é preciso definir partes do raciocínio habermasiano para conectá-lo às assertivas acima postas, tais como a noção do agir comunicativo e estratégico. No primeiro há um pensamento racional aberto, no sentido de aderir (ou não) aos argumentos de outrem, mas sempre em um processo contínuo de diálogo (locucionário e ilocucionário), diferentemente do segundo modelo de ação, o qual não utiliza dos instrumentos linguísticos para o convencimento e sim para resultar em um sentido (efeito) pré-determinado (perlocucionário), em outras palavras, não existe espaço para flexibilização ${ }^{13}$.

Percebe-se a aproximação necessária entre 0 pensamento hermenêutico e habermasiano, na direção de que além da atividade dialogal para a compreensão através da interpretação, impõem-se a abertura a esse

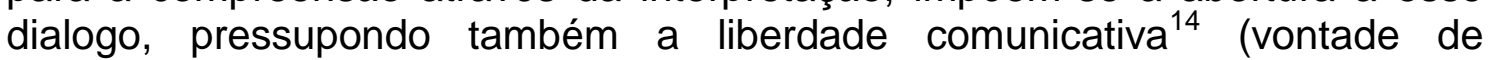
entendimento mútuo), para com o debate conceber um novo conhecimento. De 
acordo com essa ideia, assevera-se que a hermenêutica realiza a atualização ou por vezes contestação - dos conteúdos que legitimam as normas do ordenamento jurídico, haja vista que sem tal conteúdo não há sustentação para as normas ${ }^{15}$.

Nesse diapasão é possível apontar que a abertura a mecanismos que proporcionem o debate, como, por exemplo, as audiências públicas realizadas em sede do Poder Judiciário, podem ser vislumbradas como demonstração de condutas mais democráticas ${ }^{16}$, prezando igualmente por um modelo de ação comunicativa e por um perfil interpretativo no mesmo sentido (dialogal). Cita-se a situação supra apenas como demonstração de uma alteração de rumos, inclinando-se mais à comunicação (agir comunicativo e hermenêutica), em detrimento ao pensamento estratégico, cabendo frisar que tal mudança pode ser notada em outros poderes estatais.

Delineados os traços básicos que elevam o patamar da linguagem, combinando o fenômeno comunicativo ao interpretativo, passa-se a face final desse item, mais precisamente, o fator informação. Para a formação de uma pré-compreensão e, consequentemente, do debate sobre um assunto, faz-se forçosa a assimilação de um mínimo de informações, tendo como prisma orientador um pensamento democrático-comunicativo; tal conteúdo deve ter como requisito a verdade, visto que esta é um fator decisivo para estrutura de um entendimento mútuo ${ }^{17}$.

Nesse sentido, tendo delimitado a relevância da linguagem e dos processos comunicativos, passa-se à apreciação dos meios de comunicação como um serviço público (exercido por entes privados) e os direitos fundamentais com eles relacionados, retomando-se posteriormente o tema da verdade, de maneira a conjugar o pensamento habermasiano ao entendimento dos direitos informativos, na formação das ações comunicativas entre os cidadãos.

\section{MEIOS DE COMUNICAÇÃO COMO SERVIÇO PÚBLICO (PRIVADO) E OS DIREITOS FUNDAMENTAIS NA SOCIEDADE DEMOCRÁTICA}

Antes do estudo dos meios de comunicação como um serviço público desempenhado por particulares ou do papel desempenhado por estes no âmago da democracia brasileira, faz-se necessária à contextualização dos direitos fundamentais envolvidos pelo tema.

O texto proclamado pela Constituição de 1988 deu início a nova fase no direito pátrio, trazendo consigo forte estrutura axiológica, tendo como base angular a dignidade humana ${ }^{18}$. Esse princípio é o núcleo do qual provêm diversas variações específicas, haja vista que a partir dele se deduzem os demais princípios constitucionais e direitos fundamentais ${ }^{19}$.

A dificuldade conceitual resultante da abstração desse princípio não impede uma compreensão mínima da dignidade humana, entendendo-se o citado princípio como fundamento protetor do ser humano em sua 
individualidade, externando uma posição de respeito e, ao mesmo tempo, percebendo o seu caráter único em sua existência, afastando qualquer tratamento do homem como objeto (influência da concepção kantiana) ${ }^{20}$.

A partir do prisma da dignidade, subtrai-se a proteção das palavras proferidas pelos seres humanos (a manifestação da linguagem), que estão aplacadas pela liberdade de expressão, a qual se particulariza com outros direitos fundamentais: a) a liberdade de imprensa e b) informação ${ }^{21}$.

Inicia-se o exame da matéria pela a liberdade de imprensa, diferenciando-se das demais liberdades pela sua especificidade quanto ao meio de propagação de notícias e informações, mesmo o último ensejo detém suas minúcias, capazes de diferir o direito à informação da liberdade de imprensa ${ }^{22}$, tendo cada um deles características próprias. A última alusão é representada com os deveres da atividade comunicativa da imprensa, chamados de: dever geral de cuidado, dever de veracidade e o dever de pertinência.

Os deveres impostos ao exercício da liberdade de imprensa intentam estabelecer ordem ao uso deste direito fundamental, considerando-se que requisitos como a prudência (cuidado) ou a pertinência (nexo causal entre o fato e a notícia veiculada) são importantes para transparência informativa. Das subdivisões referidas acima, comenta-se o dever de veracidade (referendando também no direito à informação), visto que esse significa o compromisso com a boa-fé. O mandamento da veracidade alude a tolerância a equívocos na atividade profissional, contudo, desde que tais erros se deem na tentativa de cumprir com os compromissos sócio-informativos da função ${ }^{23}$. Em síntese 0 comunicador se compromete com a busca da verdade, obedecendo aos padrões éticos (e constitucionais) na realização de sua atividade.

Não obstante, o requisito da veracidade possibilita outro entendimento: o da não autorização da mentira nos meios de comunicação (nutrido pela própria proteção constitucional) ${ }^{24}$.

A ramificação restante da liberdade de expressão é o direito à informação, o qual se compõe (comumente ${ }^{25}$ ) das noções de um direito a ser informado e a ter acesso às informações, facilitando à população a busca pelo conhecimento e a formação de uma pré-compreensão de várias temáticas ${ }^{26}$.

Outrossim à liberdade de imprensa, o direito à informação tem a guarida constitucional e, de maneira semelhante, quando aborda-se o direito de informar exige-se a veracidade e clareza nesta prestação ${ }^{27}$, cabendo mencionar que o requisito da veracidade é de ordem subjetiva, ou seja, adotando-se uma conduta profissional pautada pela boa-fé, apresentando entendimento semelhante ao da liberdade de imprensa ${ }^{28}$.

As construções dos direitos fundamentais à liberdade de imprensa e informação expostas contêm componentes históricos de lutas recentes (tentativa de revalorização da Constituição) ${ }^{29}$, somando-se a isso a dificuldade de ponderar os interesses privados, de cunho econômico (exigências 
mercadológicas), com as questões públicas (coletivas), visando concretizar a função social por meio de uma imprensa livre e responsável. A complexidade inserida nessa correlação é recrudescida pelo componente da democracia ${ }^{30}$, cujos pressupostos reclamam uma sociedade que tem por dever a disseminação plural da informação para acrescentar conhecimento e cultura na formação da opinião pública, bem como da própria personalidade humana, sem nenhuma espécie de censura prévia ${ }^{31}$.

Especificar o âmbito que se deseja aplacar acerca da sociedade democrática é forçoso, tendo em vista que a ótica a ser relatada é vasta, encontrando-se diversos modelos de democracia diferentes na literatura e na prática $^{32}$, mas aqui não se aterá às espécies de democracia, tampouco às discussões sobre a sua conceituação; objetiva-se tão somente dispor que o entendimento atual exige um modelo aberto ao diálogo para construção do saber plural e conjunto entre as pessoas, no sentido de incentivar a participação de todos.

Ante a exposição das liberdades comunicativas no contexto social, democrático e jurídico-constitucional, compreende-se a importância de suas ações, já que os meios de comunicação exercem efetivamente tais direitos fundamentais, apesar dos deveres sociais e democráticos, ainda vinculam-se a preocupações econômicas (atividade privada). O temor diante do poder acumulado por tais ferramentas informativas é considerável, haja vista a realização, por vezes, de uma função de "controle externo" das atividades dos demais Poderes estatais. Todavia, reflete-se sobre o equivocado entendimento dessas liberdades como direitos individuais, pertencendo aos profissionais da imprensa, pois esses direitos apesar de exercidos por órgãos e indivíduos não são próprios, ou seja, eles pertencem à coletividade ${ }^{33}$.

No compasso do pensamento coletivo e democrático na expressão desses direitos, inerentes ao agir comunicativo consciente, possibilitando debates esclarecidos e informados (veracidade) pelo povo, houve a preocupação constitucional em determinar a atividade dos meios de comunicação como sendo serviços públicos; mesmo sem afirmar expressamente no artigo 21, inciso XI, da Constituição, com a leitura conjunta do artigo 66, caput, dos atos das disposições constitucionais transitórias ${ }^{34}$, pode-se entender que esta atividade foi considerada um serviço público. Diante da relevância dessa atividade para um Estado Democrático de Direito e para a própria coletividade, o constituinte nacional preocupou-se em resguardar esse instituto, por meio de normas constitucionais, fato este que sustenta a sua defesa como serviço público ${ }^{35}$.

A fim de corroborar o entendimento recém mencionado sobre serviços públicos, refere-se a definição de Alexandre Santos de Aragão ${ }^{36}$.

Além de ser mais operacional, esse conceito também é inferível da Constituição Federal de 1988, razão pela qual o adotaremos na seguinte forma: serviços públicos são as atividades de prestação de utilidade econômicas a indivíduos determinados, colocadas pela Constituição ou pela Lei a cargo do Estado, com ou sem reserva de 
titularidade, e por ele desempenhadas diretamente ou por seus delegatários, gratuita ou remuneradamente, com vistas ao bem-estar da coletividade.

Apesar do entendimento desse artigo ser no sentido dos meios de comunicação serem considerados serviços públicos, desempenhados por entes privados, resultante de concessões, visto que são inestimáveis ao regular prosseguimento de uma sociedade dialogal e democrática, há autores que entendem em outro sentido, utilizando-se para isso da hermenêutica constitucional e de princípios (proporcionalidade), a fim de ofertar uma visão diferenciada (mais liberal) ${ }^{37}$; mesmo com tal discordância, cabe aludir que inexiste engessamento no posicionamento adotado, apenas optou-se por essa concepção por entender que oferta maior proteção aos interesses da coletividade.

Ainda, sobre a atividade dos meios de comunicação como um serviço público, este é um caso privativo, haja vista estar enquadrado no regime de concessão $^{38}$, o qual pode ser entendido como uma delegação feita de uma atividade a iniciativa privada para sua exploração ${ }^{39}$. No caso dos meios de comunicação, as concessões são justificadas, conforme já aludido anteriormente, por estarem no exercício de funções imprescindíveis do ponto de vista social, democrático e de direitos fundamentais, contribuindo para formação da opinião pública, bem informada.

Entretanto, existem riscos no desempenho da atividade comunicativa e, diante das oscilações de mercado, ou de interesses escusos, compreende-se a manutenção dos meios de comunicação como sendo um serviço público. A fim de pormenorizar esse enfoque tentar-se-á aprofundar a discussão através da apreciação dos monopólios informativos, os quais representam a figura de temor no processo comunicativo social.

\section{OS MONOPÓLIOS INFORMATIVOS E O CONDICIONAMENTO DO AGIR COMUNICATIVO}

Delineados os traços linguísticos, bem como a natureza de um serviço público realizado pela iniciativa privada, imprescindível a um caminho protetivo dos direitos fundamentais e de um agir comunicativo democrático, tem-se a última etapa deste estudo, focada nos possíveis problemas deste mesmo caminho referido ao permitirem-se inclinações demasiadamente particulares. Destarte, conduzindo-se a tal ponto de exame impende o esclarecimento de alguns aspectos da atividade (público) privada, visando ao final oportunizar um entendimento íntegro do tema.

Conforme referendado alhures o poder constitucional se irradiou em todo o ordenamento jurídico, inclusive no direito privado, mesmo este tendo apresentado resistência inicial. No entanto, o advento da base axiológica constitucional alterou o próprio eixo gravitacional do direito privado, de forma que a partir desse marco pautou-se uma remodelação mais do que somente 
das relações particulares, mas sim da própria visão econômica do Estado Democrático de Direito ${ }^{40}$.

Esse fenômeno é conhecido como a constitucionalização do direito privado $^{41}$, tendo trazido novo corpo a conceitos jurídico-civis, enaltecendo a importância hermenêutica do intérprete nas relações entre particulares (ascensão da linguagem). Sob a égide desse novo prisma constitucional, diversos institutos ganharam nova roupagem (propriedade, os contratos, as empresas), especialmente em decorrência da imputação da função social, buscando harmonizar as relações entre a autonomia privada e os demais interesses constitucionais ${ }^{42}$.

As observações acima induzem a algumas considerações, dentre elas: a) a irradiação de efeitos levou o direito privado a abandonar o seu antigo perfil puramente patrimonialista; b) estando as empresas compreendidas dentro de um ideal de cumprimento de função social, logo os meios de comunicação também se encontram nessa mesma situação, tendo em vista que são entes privados exercendo um serviço público; c) os meios de comunicação devem adimplir com a sua função social, a fim de respeitar os direitos fundamentais por eles desempenhados, ponderando questões econômicas e sociais para ofertar um desenvolvimento democrático (informação veraz) adequado à nação.

Apresentam-se aqui ressalvas ao ponto de vista econômico, pois embora o Direito tente cumprir sua parcela de responsabilidade para com a sociedade, a tarefa de modificar o panorama sócio-econômico supera suas forças, embora o Estado brasileiro demonstre preocupação nesse sentido ${ }^{43}$.

Assim, retornando aos trilhos do direito privado, merece atenção o tema dos poderes privados ${ }^{44}$, que representam uma nova realidade econômica, na qual entes particulares são capazes de deter grandes poderes, semelhantes à relação Estado-indivíduo, ocasionando a verticalização da relação privada ${ }^{45}$. Essa demonstração de poder dos particulares reforça a tese da aplicação de efeitos dos direitos fundamentais no campo privado, visto que inexiste nessas situações equilíbrio entre as partes e, portanto, há iminência de lesões aos direitos do cidadão.

Dando seguimento nesse raciocínio aponta-se como uma demonstração dos poderes privados os chamados monopólios da informação; nestes casos, empresas de comunicação detentoras de elevado poder econômico agem na veiculação condicionada de grandes parcelas informativas, podendo impor uma "ditadura informativa" (ação estratégica), já que desempenham as principais funções sócio-comunicativas. Essa espécie de conduta por parte de órgãos privados antagoniza com os fundamentos valorativos trazidos na Constituição (artigo 220, $\S 2^{\circ}$ - veda expressamente o monopólio ou oligopólio dos meios de comunicação social), além de ser incompatível com uma sociedade democrática e pluralista ${ }^{46}$. Portanto, uma situação inconstitucional do ponto de vista que não haveria resguardo adequado dos direitos fundamentais, tampouco se proporcionaria a construção digna da personalidade humana restringindo-se o acesso à informação, ao conhecimento e, consequentemente, 
estar-se-ia limitando a capacidade de um agir comunicativo consciente por parte dos indivíduos ${ }^{47}$.

A restrição a um mínimo de variação nas manifestações de opinião constrói uma nação alienada (opinião pública pobre - redução no âmbito linguístico), e tendo em vista os prejuízos possibilitados pela unicidade informativa é que não se podem aceitar tais monopólios no caminho de um crescimento social e democrático. Dessa forma, o exercício abusivo do poder econômico, especificamente nos monopólios informativos, é uma prática avessa aos interesses constitucionais, podendo ser vista como antidemocrática (e anticomunicativa $)^{48}$.

Entretanto, existem opiniões contrárias, não no sentido de apoio aos monopólios informativos, mas que negam a sua existência, sendo tal posicionamento encontrado na doutrina norte-americana ${ }^{49}$; mesmo assim, embora se respeitem opiniões em contrário, o posicionamento ora adotado não se altera, haja vista todo o aporte teórico até o momento explanado.

A negação da existência dos monopólios informativos por parte da doutrina norte-americana pode ter suas raízes na formação liberal, a qual tende a interpretações de liberalidade das ações mercadológicas, vendo nessa situação as grandes corporações da comunicação como forças de mercado e não como hegemonias de um interesse público coletivo. Embora se respeite esse posicionamento, a realidade brasileira não se enquadra nas linhas estrangeiras (havendo estudos nos quais são descritos monopólios informativos no Brasil ${ }^{50}$ ), pois sendo o país um modelo democrático de direito, há uma preocupação com a redução das desigualdades sociais, ou seja, a espécie de Estado adotada exige uma postura diferenciada no sentido da igualdade material aos cidadãos, o que, sem dúvida, não se coaduna com a formação de monopólios informativos.

Ademais, além das incompatibilidades contextuais nacionais, inclusive, com o modelo de Estado adotado, a base crítica aos monopólios são os próprios direitos fundamentais, os quais, nessa situação, são ofendidos, primeiramente, conforme já aludido, no sentido de que com a adoção desses monopólios ocorre o não cumprimento da missão democrática devido à redução na pluralidade informativa. Cabe referir que juntamente ao pensamento defensor dos direitos fundamentais e do pluralismo informativo democrático está a limitação das fontes como um redutor do conhecimento e, por conseguinte, funcionando como um limitador da comunicação, já que a possibilidade de condicionamento (informações inverídicas) informativo pelos monopólios poderá viciar as inter-relações comunicativas (vício no agir comunicativo).

À vertente crítica iniciada acima se acresce o requisito (inserido através da ética) da função social, incompatibilizando-se com o pensamento econômico restritivo. Nesse sentido, os monopólios informativos são inconciliáveis com a concepção de função social, pois esta visa equilibrar interesses díspares (privados e públicos) para com isso impedir abusos por parte do mercado que inflijam danos aos direitos fundamentais (como as liberdades de expressão, 
imprensa e informação). Desta forma, pode-se afirmar que estando as atividades informativas compreendidas na órbita de atuação do direito privado, mesmo que desempenhando um serviço público, os meios de comunicação contemplam uma função social, decorrente de seu vínculo direto com os direitos fundamentais (tanto no sentido de efetivação quanto de violação) ${ }^{51}$ e, portanto, não podem aceitar ações antidemocráticas como os monopólios.

Desse modo, mesmo com temores de abusos de poder ${ }^{52}$, entende-se que é possível estruturar a atividade econômica com o cumprimento das funções sociais por parte dos meios de comunicação, auferindo assim o cumprimento de suas incumbências, executando adequadamente o serviço público, com lucro. Contudo, a vigilância (sem censura prévia) sobre a atividade é imperiosa, tanto pela efetivação dos direitos fundamentais, quanto por se estar diante de função inerente (prestação de informações verdadeiras) à formação de uma pré-compreensão mínima ao exercício do agir comunicativo-democrático na sociedade.

\section{CONSIDERAÇÕES FINAIS}

A partir do viés linguístico disposto no trabalho, percebeu-se a sua importância na sociedade contemporânea, tendo esta constatação sido realizada através da composição hodierna da hermenêutica e do agir comunicativo habermasiano, ambos indicando o caminho do diálogo como algo precioso à formação humana atual. Conjugado com esse pensamento aprofundou-se o estudo dos meios de comunicação, os quais são responsáveis pela veiculação informativa, imprescindível à formação da pré-compreensão e inerente a um agir comunicativo, bem como são responsáveis pela efetivação de direitos fundamentais, como a liberdade de imprensa e o direito à informação.

Observada com clareza a ligação entre os dois pensamentos, asseverou-se a relevância da atividade comunicativa, visto a sua disposição como um serviço público, já que imperiosa ao próprio modelo estatal e social democrático. Ademais, mesmo sendo realizado pela iniciativa privada, a forma de concessão é o resguardo protetivo do ente público para com a sociedade.

Diante do exposto, a possibilidade da instituição de monopólios privados no setor de comunicações é algo a ser refutado, pois sua constituição ofende uma série de critérios axiológicos constitucionais, como as concepções de função social e sociedade democrático-pluralista. A manipulação informativa devido a ideologias privadas (ação estratégica) pode viciar esse serviço, suprimindo não somente um requisito ético profissional (e do próprio direito fundamental - liberdade de imprensa e direito à informação), mas um componente necessário à acumulação de conhecimento (pré-compreensão). Assim é possível entender que o perecimento da veracidade na informação é capaz de causar um vício de consentimento no cidadão, de maneira a lesar as suas futuras ações no sentido comunicativo, haja vista a existência do vício anterior; dito isso se justifica o resguardo da atividade como um serviço público, tendo em vista os possíveis excessos dos chamados poderes privados, para 
dessa forma anteparar o caminho livre, comunicativo e democrático da sociedade brasileira.

\title{
THE MEDIA AS A PARADIGM CONSTITUTIONAL DEMOCRACY IN SOCIAL COMMUNICATIVE PROCESS
}

\begin{abstract}
The present study, from a constitutional vision, is based on combined vision between needs about information-communication for the democratic process, focusing on the role of the media, considering that these are important providers of information in modern society. The performance of these is by private entities, but exercising a public function, as it helps in enforcing fundamental rights and in communication process that is essential to democracy. The article show as a questioning whether the action of monopolies in the information activities of the media is able to vitiate the exercise of citizen communication, since the truth is professional and ethical component inherent in both communicative actions, and in which case, the truth can be "conditioned" by special interests. In order to answer the problem, the construction was structured from the importance of language, hermeneutical base, and the communicative thought of Habermas, and we can with this connect it with the activity of the media, fundamental rights and the vision of democracy, based on communicative action, to refer in the end to the negative character of the influence of the monopolies of private entities in the actions of society, keeping in mind the possibility of addiction about the true, consequently about the communicative process and democratic, by individual interests.
\end{abstract} service.

KEYWORDS: Constitution. Democracy. Private entities. Media. Public

\section{NOTAS}

1 Especialista em Direitos Fundamentais e Constitucionalização do Direito - PUC/RS. Mestrando em Direito pela Universidade de Santa Cruz do Sul (UNISC). Santa Cruz do Sul - RS. Brasil. Integrante dos Grupos de Estudos "Intersecções jurídicas entre o público e privado" e "Direito de Autor", coordenados pelo Prof. Pós-Doutor Jorge Renato dos Reis. Participante dos projetos de pesquisa "O direito de autor no constitucionalismo contemporâneo: um estudo comparado Brasil x Uruguai" e "Políticas públicas de educação para o consumo". Bolsista CAPES. Advogado - felipevdias@gmail.com.

2 Pós-Doutor em Direito pela Universidade de Salerno-Itália, Professor-Coordenador do Programa de Pós-graduação em Direito - Mestrado e Doutorado da UNISC. Santa Cruz do Sul - RS. Brasil. Coordenador dos Projetos "Políticas públicas de educação para o consumo" e "O direito de autor no constitucionalismo contemporâneo: um estudo comparado Brasil x Uruguai". Coordenador dos Grupos de Estudos e Pesquisas (CNPQ) "Intersecções jurídicas entre o público e o privado" e "Direito de Autor". Advogado jreis@viavale.com.br.

3 LUCAS, Doglas Cesar. Hermenêutica filosófica e os limites do acontecer do direito numa cultura jurídica aprisionada pelo "procedimentalismo metodológico". In: LUCAS, Doglas Cesar; SPAREMBERGER, Raquel Fabiana Lopes. Olhares hermenêuticos sobre o direito: em busca de sentido para os caminhos do jurista. 2 ed. ljuí: Unijuí, 2007. p. 24. 
4 MAGALHÃES FILHO, Glauco Barreira. Hermenêutica e unidade axiológica da constituição. 2 ed. Belo Horizonte: Mandamentos, 2002. p. 63 - 64. "Sob a influência desse pensamento nasceu, na França, Escola de Exegese, enfatizando a teoria da plenitude da lei e um método lógico-formal de aplicação do Direito. A aplicação do Direito era vista como mera subsunção de fatos à norma, perfazendo um silogismo judicial no qual a norma era a premissa maior; o fato, a premissa menor; e a sentença, a conclusão. Posteriormente, surgiu a Jurisprudência dos Conceitos (Puchta) e o Pandectismo (Windscheid) na Alemanha, bem como a Escola Analítica Inglesa (Austin), todas adotando métodos lógicoformais e, assim, revelando-se semelhantes à Escola de Exegese. Debaixo das orientações teóricas mencionadas, deu-se o fortalecimento nascente, bem como da noção de Estado de Direito, entendido como aquele no qual há o governo de leis".

5 BARROSO, Luís Roberto. Fundamentos teóricos e filosóficos do novo direito constitucional brasileiro (pós-modernidade, teoria crítica e pós-positivismo). In: BARROSO, Luís Roberto (Org.). A nova interpretação constitucional: ponderação, direitos fundamentais e relações privadas. 2 ed. Rio de Janeiro: Renovar, 2006. p. 26 - 27. "A superação histórica do jusnaturalismo e o fracasso político do positivismo abriram caminho para um conjunto amplo e ainda inacabado de reflexões acerca do Direito, sua função social e sua interpretação. $O$ pós-positivismo é a designação provisória e genérica de um ideário difuso, no qual se incluem a definição das relações entre valores, princípios e regras, aspectos da chamada nova hermenêutica e a teoria dos direitos fundamentais".

6 Apresentando a defesa do positivismo está o artigo de COMANDUCCI, Paolo. Uma defesa do positivismo metodológico. In: DIMOULIS, Dimitri; DUARTE, Écio Oto (Coords.). Teoria do direito neoconstitucional: superação ou reconstrução do positivismo jurídico? São Paulo: Método, 2008.

7 ROHDEN, Luiz. Hermenêutica filosófica. São Leopoldo: Unisinos, 2003. p. 65. "A virada hermenêutica epistemológica, isto é, da moderna à ontológica, expressa-se no termo e significado do hermeneutic turn, iniciado por Heidegger como hermenêutica da facticidade enquanto filosofia hermenêutica e levada adiante por Gadamer enquanto hermenêutica filosófica".

8 GRONDIN, Jean. Introdução à hermenêutica filosófica. São Leopoldo: Unisinos, 1999. p. 186. "Ele inicia pela descoberta de Heidegger, da estrutura ontológica do círculo hermenêutico. Ontológico significa aqui, como tão frequentemente em Gadamer: universal. O círculo é universal, porque cada compreensão é condicionada por uma motivação ou por um pré-conceito. Os pré-conceitos - ou a pré-compreensão - escreve Gadamer provocadoramente, valem, de certa forma, como "condições de compreensão" transcendentais. A nossa historicidade não é uma limitação, e sim um princípio de compreensão. Nós compreendemos e tendemos para uma verdade, porque somos guiados neste processo por expectativas sensoriais". Cabe aqui também mencionar a obra original de GADAMER, Hans-Georg. Verdade e método l: traços fundamentais de uma hermenêutica filosófica. 7 ed. Petrópolis: Vozes, 2005. p. 355. Bem como o pensamento nesse sentido de HABERMAS, Jürgen. Direito e democracia: entre facticidade e validade I. Rio de Janeiro: Tempo Brasileiro, 1997. p. 247 - 248.

9 STRECK, Lenio Luiz. Hermenêutica jurídica $e(m)$ crise: uma exploração hermenêutica da construção do direito. 3 ed. Porto Alegre: Livraria do Advogado, 2001. p. 193.

10 OLIVEIRA, Manfredo Araújo de. Reviravolta lingüístico-pragmática na filosofia contemporânea. São Paulo: Edições Loyola, 2001. p. 233.

11 STRECK, Lenio Luiz. A revelação das "obviedades" do sentido comum e o sentido (in)comum das "obviedades" reveladas. In: CAMPUZANO, et al. O poder das metáforas: homenagem aos 35 anos de docência de Luis Alberto Warat. Porto Alegre: Livraria do Advogado, 1998. p. 54.

12 GADAMER, Hans-Georg. Verdade e método l: traços fundamentais de uma hermenêutica filosófica. 7 ed. Petrópolis: Vozes, 2005. p. 502 - 503. "Por isso, o significado de um texto não se pode comparar com um ponto de vista fixo, inflexível e obstinado, que coloca sempre a mesma pergunta àquele que procura compreender: como o outro pode chegar a uma opinião tão absurda? Nesse sentido, na compreensão não se trata seguramente de um 'entendimento histórico' que reconstruiria exatamente o que retrata o texto. Ao contrário, pensamos compreender o próprio texto. Mas isso significa que, no redespertar o sentido do texto já se encontram sempre implicados os pensamentos próprios do intérprete. Nesse sentido o próprio horizonte do intérprete é determinante, mas também ele não como um ponto de vista próprio que se mantém ou se impõe, mas como uma opinião e possibilidade 
que se aciona e coloca em jogo e que ajuda a apropriar-se verdadeiramente do que se diz no texto. Acima descrevemos isso como fusão de horizontes. Agora podemos reconhecer nisso a forma de realização da conversação, graças à qual chega à expressão uma 'coisa' que não é somente minha ou de meu autor, mas uma coisa comum a ambos". Cita-se outras duas obras nesse sentido. PEREZ LUÑO, Antonio Enrique. Derechos humanos, estado de derecho y constitución. 9 ed. Madrid: Tecnos, 2005. p. 269 - 271. e OLIVEIRA, Manfredo Araújo de. Reviravolta lingüístico-pragmática na filosofia contemporânea. São Paulo: Edições Loyola, 2001. p. 238.

13 HABERMAS, Jürgen. Consciência moral e agir comunicativo. Rio de Janeiro: Tempo Brasileiro, 1989. p. 79. "Chamo de comunicativas às interações nas quais as pessoas envolvidas se põem de acordo para coordenar seus planos de ação, o acordo alcançado em cada caso medindo-se pelo reconhecimento intersubjetivo das pretensões de validez. No caso de processos de entendimento mútuo lingüísticos, os atores erguem com seus atos de fala, ao se entenderem uns com os outros sobre algo, pretensões de validez, mais precisamente, pretensões de verdade, pretensões de correção e pretensões de sinceridade, conforme se refiram a algo no mundo objetivo [...] a algo no mundo social comum [...] ou a algo no mundo subjetivo próprio [...] Enquanto que no agir estratégico um atua sobre o outro para ensejar a continuação desejada de uma interação, no agir comunicativo um é motivado racionalmente pelo outro para uma ação de adesão - e isso em virtude do efeitos ilocucionário de comprometimento que a oferta de um ato de fala suscita".

HABERMAS, Jürgen. Direito e democracia: entre facticidade e validade I. Rio de Janeiro: Tempo Brasileiro, 1997. p. 156. "Liberdade comunicativa só existe entre atores que desejam entender-se entre si sobre algo num enfoque performativo e que contam com tomadas de posição perante pretensões de validade comunicativa, que depende sempre de uma relação intersubjetiva, explica por que ela se liga a obrigações ilocucionárias".

15 HABERMAS, Jürgen. Consciência moral e agir comunicativo. Rio de Janeiro: Tempo Brasileiro, 1989. p. $82-83$.

16 HABERMAS, Jürgen. Direito e democracia: entre facticidade e validade I. Rio de Janeiro: Tempo Brasileiro, 1997. p. 158. "[...] o princípio da democracia só pode aparecer como núcleo de um sistema de direitos".

17 HABERMAS, Jürgen. Consciência moral e agir comunicativo. Rio de Janeiro: Tempo Brasileiro, 1989. p. $167-168$.

18 CANOTILHO, José Joaquim Gomes. Direito constitucional. 7 ed. Coimbra: Almedina, 2004. p. 225.

19 SARLET, Ingo Wolfgang. Dignidade da pessoa humana e direitos fundamentais na constituição federal de 1988. 5 ed. Porto Alegre: Livraria do Advogado, 2008. p. 83. "Se, por um lado, consideramos que há como discutir - especialmente na nossa ordem constitucional positiva - a afirmação de que todos os direitos e garantias fundamentais encontram seu fundamento direto, imediato e igual na dignidade da pessoa humana, do qual seriam concretizações, constata-se, de outra parte, que os direitos e garantias fundamentais podem - em princípio e ainda que de modo e intensidade variáveis - , ser reconduzidos de alguma forma à noção de dignidade da pessoa humana, já que todos remontam à idéia de proteção e desenvolvimento das pessoas, de todas as pessoas, como bem destaca Jorge Miranda".

20 SARLET, Ingo Wolfgang. Dignidade da pessoa humana e direitos fundamentais na constituição federal de 1988. 5 ed. Porto Alegre: Livraria do Advogado, 2008. p. 37. "De qualquer modo, incensurável, isto sim, como teremos oportunidade de demonstrar no próximo segmento, é a permanência da concepção kantiana no sentido de que a dignidade da pessoa humana, esta (pessoa) considerada como fim, e não como meio, repudia toda e qualquer espécie de coisificação e instrumentalização do ser humano". Em igual sentido a posição de, RODRIGUEZ, Javier Llobet. Derechos humanos y justicia penal. Heredia: Poder Judicial, Depto. De Artes Gráficas, 2007. p. 45-46.

$21 \mathrm{O}$ autor apresenta diferenciação sobre a liberdade de expressão e as liberdades de imprensa e informação SABAU, José Ramón Pólo. Libertad de expresión y derecho de acesso a los médios de comunicación. Madrid: CEPC, 2002. p. 15.

22 BARROSO, Luís Roberto. Colisão entre liberdade de expressão e direitos de personalidade. Revista latino-americana de estudos constitucionais. São Paulo: Del Rey. n. 5, janeiro junho, 2005. p. 319.

23 PEREIRA, Guilherme Döring Cunha. Liberdade e responsabilidade dos meios de comunicação. São Paulo: Revista dos Tribunais, 2002. p. 156. "Ora, não é de esquecer-se 
que o erro cometido de boa-fé, no afã de acertar e de avançar e de trazer progresso, tem papel indiscutivelmente positivo, também eticamente. É mais nobre errar por ter tentado algo valioso do que se omitir por medo de sanções ou represálias". Menciona-se também nesse sentido a abordagem de Owen Fiss, o qual traz entendimento semelhante, mas com base em um caso julgado nos Estados Unidos em 1964, pela Suprema Corte. FISS, Owen. La ironía de la libertad de expresión. Barcelona: Gedisa, 1999. p. 72.

$\mathrm{O}$ autor traz a perspectiva do direito uruguaio, no entanto, analogicamente suas colocações encaixam-se igualmente no sentido de legitimidade do direito à resposta, refutando a mentira veiculada através do uso da liberdade de imprensa. TERRA, Eduardo Héguy. La responsabilidad de los medios de comunicación. Montevideo: Fundación Fontana Minelli, 2001. p. 55. "El derecho de respuesta, polémico en otros países, en el derecho positivo uruguayo se le reconoce a toda persona física o jurídica afectada [...] Como lo expresa la doctrina, la réplica se funda en el derecho a la verdad, pero no porque ella esté contenida en la respuesta, sino porque presentando las dos versiones de los hechos habrá más elementos de juicio que faciliten accender a la verdad". Contribui também ao afastamento da mentira os fundamentos de Kant, com base na dignidade humana, conforme expõe HÄBERLE, Peter. Os problemas da verdade no estado constitucional. Porto Alegre: Sergio Fabris, 2008. p. 64.

MIRAGEM, Bruno. Liberdade de imprensa e proteção da personalidade no direito brasileiro: perspectiva atual e visão de futuro. Revista trimestral de direito civil. Rio de Janeiro: Padma. v. 40, outubro - dezembro, 2009. p. 25.

26 CASTRO, Carlos Roberto Siqueira. A constituição aberta e os direitos fundamentais: ensaios sobre o constitucionalismo pós-moderno e comunitário. 2 ed. Rio de Janeiro: Forense, 2010. p. 437. "O direito a informação, que compreende de modo amplo o direito a ser informado e a ter acesso às informações necessárias ou desejadas para formação do conhecimento, constitui por certo, juntamente com o direito à vida, a mais fundamental das prerrogativas humanas, na medida em que o saber determina o entendimento e as opções da consciência, o que distingue os seres inteligentes de todas as demais espécies que exercitam o dom da vida. Trata-se, também, do pré-requisito mais essencial ao regime democrático, sabido que os indivíduos e sobretudo um povo desinformado e destituído da capacidade de crítica para avaliar o processo social e político acham-se proscritos das condições da cidadania que dão impulso aos destinos das nações".

27 Apresenta a prestação das informações verdadeiras como um dever inerente ao exercício da liberdade dos meios de comunicação a autora SCHMITT, Rosane Heineck. Direito à informação - liberdade de imprensa $x$ direito à privacidade. In: SARLET, Ingo Wolfgang (Org.). A constituição concretizada: construindo pontes com o público e o privado. Porto Alegre: Livraria do Advogado, 2000. p. 219.

28 LIMBERGER, Têmis. O direito à intimidade na era da informação: a necessidade de proteção dos dados pessoais. Porto Alegre: Livraria do Advogado, 2007. p. 134. BONAVIDES, Paulo. Teoria do estado. 5 ed. São Paulo: Malheiros, 2004. p. 324.

30 Mesmo não sendo o enfoque desejado, registra-se aqui o conhecimento de uma grande quantidade de obras tratando do tema democracia, bem como a existência de espécies diferentes, mas no caso deste estudo o interesse reserva-se a uma visão de sociedade democrática. Mesmo assim, citar-se uma obra que aprofunda essa questão. FERRARI, Vincenzo. Democracia e informação no final do século XX. In: GUIMARÃES, César; JUNIOR, Chico (Org.). Informação e democracia. Rio de Janeiro: EdUERJ, 2000. p. 164.

31 FERRARI, Vincenzo. Democracia e informação no final do século XX. In: GUIMARÃES, César; JUNIOR, Chico (Org.). Informação e democracia. Rio de Janeiro: EdUERJ, 2000. p. 165 - 166. "Se democracia significa liberdade e igualdade no gozo de direitos e de oportunidades, parece claro que a informação livre, como acentuado no início, dela constitui fundamento um fundamento essencial [...] Compreende-se assim 'informação' não é somente 'o ato de informar' como diz o vocabulário, mas em geral é parte essencial do processo de formação de conhecimentos, de opiniões e, portanto, da própria personalidade do indivíduo: a parte que age mediante a interação do sujeito com o mundo externo. A falta de informação bloqueia o desenvolvimento da personalidade, tornando-a asfixiada. Outrossim, uma informação unilateral, advinda de uma só fonte, mesmo que quantitativamente rica e qualitativamente sofisticada, direciona a personalidade para canais preestabelecidos, limitando objetivamente a oportunidade de escolha e a capacidade crítica do indivíduo, prejudicando desta forma a sua participação nos processo democráticos. [...] A relação entre democracia e informação é, portanto, biunívoca, de coessencialidade, no 
sentido de que uma não pode existir sem a outra e o conceito de uma comporta o conceito da outra". Em igual sentido a posição de SOUZA, Sérgio Ricardo de. Controle judicial dos limites constitucionais à liberdade de imprensa. Rio de Janeiro: Lumen Juris, 2008. p. 103 104.

32 A obra de Habermas traz algumas dessas espécies HABERMAS, Jürgen. $A$ inclusão do outro - estudos de teoria política. 2 ed. São Paulo: Edições Loyola, 2004. p. 277 - 292. ou conforme acresce LEAL, Rogério Gesta. Esfera Pública e Participação social: possíveis dimensões jurídico-políticas dos direitos civis de participação social no âmbito da gestão dos interesses públicos no Brasil. In: LEAL, Rogério Gesta. Administração pública compartida no Brasil e na Itália: reflexões preliminares. Santa Cruz do Sul: Edunisc, 2008. p. 182. "Daqui, chega-se, então, à concepção habermasiana de política democrática deliberativa, baseada em um modelo teórico dual, relacionado não apenas com a formação da vontade, institucionalizada no complexo parlamentar, mas também um conjunto espontaneamente gerado de arenas políticas informais, dialogicamente discursivas e democráticas, e ao próprio contexto cultural e base social respectivos, afigurando-se esta democracia deliberativa como uma oposição binária entre o plano formal e institucionalizado da democracia e os domínios informais e anárquicos de formação e opinião. Esta noção de política democrática deliberativa, por sua vez, assenta-se também na teoria da comunicação habermasiana, cujo ideal regulador é um modelo de prática discursiva dialógica, face-a-face e orientada para o entendimento mútuo, através exclusivamente da força do melhor argumento". BINENBOJM, Gustavo. A Constitucionalização do Direito Administrativo no Brasil: Um Inventário de Avanços e Retrocessos. In: BARROSO, Luís Roberto (Org.). A reconstrução democrática do direito público no Brasil. Rio de Janeiro: Renovar, 2007. p. 524. "A democracia, a seu turno, consiste em um projeto moral de autogoverno coletivo, que pressupõe cidadãos que sejam não apenas os destinatários, mas também os autores das normas gerais de conduta e das estruturas jurídico-políticas do Estado".

33 GUERRA, Sidney Cesar Silva. A liberdade de imprensa e o direito à imagem. 2. ed. Rio de Janeiro: Renovar, 2004. p. 82. "A liberdade de imprensa não é um direito dos profissionais da imprensa mas toda sociedade e, portanto, deve ser protegido por todos nós, tendo em vista que estes direitos, como demonstrado, foram conquistados com muita luta e de forma bastante lenta".

34 Art. 21. Compete à União: [...]XI - explorar, diretamente ou mediante autorização, concessão ou permissão, os serviços de telecomunicações, nos termos da lei, que disporá sobre a organização dos serviços, a criação de um órgão regulador e outros aspectos institucionais; e Art. 66. São mantidas as concessões de serviços públicos de telecomunicações atualmente em vigor, nos termos da lei.

35 ARAGÃO, Alexandre Santos de. Direito dos Serviços Públicos. Rio de Janeiro: Forense, 2007. p. 132. "[...] o mesmo não se dá com os serviços públicos, atividades econômicas lato sensu que não tem ínsita em si a integração à esfera pública ou privada, ou seja, são atividades que, ontologicamente, poderiam pertencer a uma outra esfera, mas que o Constituinte ou o legislador, em função de uma avaliação do interesse da coletividade em determinado momento histórico, entendeu que o Estado deveria, para cumprir suas funções constitucionais de proteção dos liames sociais, tomar a atividade como sua".

36 ARAGÃO, Alexandre Santos de. Direito dos Serviços Públicos. Rio de Janeiro: Forense, 2007. p. 157. Também trazem noções conceituais sobre serviço público os seguintes autores MEIRELLES, Hely Lopes. Direito administrativo brasileiro. 36 ed. São Paulo: Malheiros, 2010. p. 350 - 352. e DI PIETRO, Maria Sylvia Zanella. Direito administrativo. 24 ed. São Paulo: Atlas, 2011. p. 99 - 106.

37 ARAGÃO, Alexandre Santos de. Direito dos Serviços Públicos. Rio de Janeiro: Forense, 2007. p. 235. "É, então, a letra da Constituição (ao se referir à "autorização" no art.21), somada à sua necessária evolução e aos paradigmas da hermenêutica constitucional, que nos leva a afirmar haver serviços de telecomunicações e outros enumerados nos incisos XI e XII do art. 21, que podem, observado o princípio da proporcionalidade, em seus aspectos omissivo e comissivo, ser despublicizados, tornando-se atividades econômicas privadas de interesse público".

38 CEZNE, Andrea Nárriman. O conceito de serviço público e as transformações do Estado contemporâneo. Revista de informação legislativa. Brasília. Número 167, 2005. p. 5. "A distinção baseia-se na idéia segundo a qual serviços públicos privativos seriam aqueles cujo exercício somente poderia se dar por meio de regime de concessão. Grau elenca como serviços públicos não privativos a saúde e a educação, agrupando-os como atividades que 
têm por substrato atividade econômica, podendo tanto ser desenvolvidas pelo Estado como pela iniciativa privada".

ARAGÃO, Alexandre Santos de. Direito dos Serviços Públicos. Rio de Janeiro: Forense, 2007. p. 568. "É a delegação contratual e remunerada da execução de serviço público a particular para por sua conta e risco explorá-lo de acordo com as disposições contratuais e regulamentares pertinentes, por determinado prazo, findo o qual os bens afetados à prestação do serviço, devidamente amortizados, voltam ou passam a integrar o patrimônio público". Outra obra que aborda o tema é: GRECO, Marco Aurélio. Aspectos da concessão de serviço público. Revista de direito público. São Paulo: Revista dos Tribunais. Volume 21.

40 No sentido da aplicação dos direitos fundamentais nas relações interprivadas tem-se as palavras de SILVA, Virgílio Afonso da. A constitucionalização do direito. Os direitos fundamentais nas relações entre particulares. São Paulo: Malheiros, 2005. p. 41 - 43.

41 SARMENTO, Daniel. Direitos Fundamentais e relações privadas. 2 ed. Rio de Janeiro: Lúmen Juris, 2010. p. 76. "Cumpre, por outra banda, destacar que a constitucionalização do Direito Privado não se resume ao acolhimento, em sede constitucional, de matérias que no passado eram versadas no Código Civil. O fenômeno é muito mais amplo, e importa na '(...) releitura do Código Civil e das leis especiais à luz da Constituição Republicana"'.

42 TEPEDINO, Gustavo. Normas constitucionais e direito civil na construção unitária do ordenamento. SOUZA NETO, Cláudio Pereira de; SARMENTO, Daniel (Coord.). A constitucionalização do direito: fundamentos teóricos e aplicações específicas. Rio de Janeiro: Lumen Júris, 2007. p. 310. "Mais de uma década depois, a promulgação do Código Civil de 2002 impôs a reflexão acerca dos paradigmas axiológicos que devem nortear 0 intérprete na reconstrução dos institutos de direito privado. A este respeito, deve-se observar que o direito civil assistiu ao deslocamento de seus princípios fundamentais do Código Civil para a Constituição. Tal realidade, reduzida por muitos a fenômeno de técnica legislativa, ou mesmo à mera atecnia, revela profunda transformação dogmática, em que a autonomia privada passa a ser remodelada por valores não patrimoniais, de cunho existencial, inseridos na própria noção de ordem pública. Propriedade, empresa, família, relações contratuais, em especial da dignidade da pessoa humana, não mais havendo setores imunes a tal incidência axiológica, espécies de zonas francas para a atuação da autonomia privada. A autonomia privada deixa de configurar um valor em si mesma, e será merecedora de tutela somente se representar, em concreto, a realização de um valor constitucional".

43 Existem diversas propostas inovadoras no campo econômico democrático, inclusive reestruturando as próprias concepções de trabalho e do tempo despendido com as atividades, no caminho para uma existência humana saudável e harmônica com a sociedade e o próprio planeta. Entre elas podem-se mencionar duas obras de ângulos diferentes, a primeira com um enfoque reeducativo econômico-global e a outra numa revisão do desenvolvimento humano no planeta, são elas: DOWBOR, Ladislau. Democracia econômica: alternativas de gestão social. Petrópolis: Vozes, 2008 e SACHS, Ignacy. Caminhos para o desenvolvimento sustentável. 3 ed. Rio de Janeiro: Garamond, 2008.

44 A hodierna relação entre poder político (estatal) e econômico (privado) é apreciada com propriedade por Dowbor, que prega a democratização da economia exatamente por compreender a grande influência e amplitude deste poder privado, inclusive, sobre o poder do Estado. O autor chama atenção para o fato de as sociedades modernas muito se preocuparem com a democracia no âmbito político, mas, contemporaneamente tem-se verificado o surgimento de um amplo poder econômico, de feição privada, e que, portanto, não é submetido aos padrões convencionais de controle. Tal fato pode ser exemplificado pela existência de empresas e grupos econômicos que apresentam orçamentos muito mais elevados que boa parte de países inteiros. Nas palavras do autor: DOWBOR, Ladislau. Democracia econômica: alternativas de gestão social. Petrópolis: Vozes, 2008. p. 54.

45 UBILLOS, Juan María Bilbao. ¿En qué medida vinculan a los particulares los derechos fundamentales? In: SARLET, Ingo Wolfgang (Org.). Constituição, direitos fundamentais e direito privado. 3 ed. Porto Alegre: Livraria do Advogado, 2010. p. 220 - 221. "“Frente a esa concepción unidireccional de los derechos de libertad, en el Estado social de derecho se abre paso um nuevo entendimiento de las relaciones Estado-sociedad, que acaba desenmascarando, poniendo al descubierto la ficción que vinculaba el disfrute de la libertad en la esfera social a la simple afirmación del principio de igualdad jurídica. Hoy como ayer la realidad desmiente la existencia de una paridad jurídica en buena parte de las relaciones que establan los sujetos privados. El Derecho privado conoce también el fenómeno de la 
autoridad, del poder, como capacidad de determinar o condicionar jurídicamente o de facto las decisiones de otros, de influir eficazmente en el comportamiento de otros, de imponer la propia voluntad. Basta con mirar alreddedor y observar atentamente la realidad que nos rodea. Es un hecho fácilmente constatable la progresiva multiplicación de centros de poder privados y la enorme magnitud que han adquirido algunos de ellos. Representan en la actualidad una amenaza nada desdeñable para las libertades individuales. El poder ya no está concentrado en el aparato estatal, está disperso, diseminado en la sociedad. Al fin y al cabo, el fenómeno del poder como expresión de una situación de deisgualdad es indisociable de las relaciones humanas, es inherente a toda organización social".

46 Ao abordar a temática relativa à verdade, Häberle se depara com problemáticas envolvendo a democracia pluralista e o Estado, bem como aborda questões relativas à imprensa e à informação. HÄBERLE, Peter. Os problemas da verdade no estado constitucional. Porto Alegre: Sergio Fabris, 2008. p. 113. "Em particular, a democracia pluralista do Estado constitucional depara-se diretamente com três áreas problemáticas da questão da verdade: nos conflitos sobre a relação entre <<verdade e maioria >>, no entendimento da formação da opinião pública da sociedade e, como parte disso, na limitação da liberdade de imprensa a favor do interesse de outros valores protegidos e as suas orientações referentes à crônica jornalística <<fidedigna à verdade>> (ao invés da $<<$ mentira mediática>>)". Em sentido complementar menciona-se Marcelo Campos Galuppo e sua construção acerca do pluralismo e da sua formatação no Estado Democrático de Direito. GALUPPO, Marcelo Campos. Hermenêutica constitucional e pluralismo. In: SAMPAIO, José Adércio Leite; CRUZ, Álvaro Ricardo de Souza (Coord.). Hermenêutica e jurisdição constitucional. Belo Horizonte: Del Rey, 2001. p. 61.

47 FERRARI, Vincenzo. Democracia e informação no final do século XX. In: GUIMARÃES, César; JUNIOR, Chico (Org.). Informação e democracia. Rio de Janeiro: EdUERJ, 2000. p. 171. "Tanto o monopólio público, quanto o monopólio privado das fontes informativas é incompatível com a democracia: uma democracia deve impedir ambos com leis antitrust no setor privado e com garantia de gestão pluralista no setor público. [...] Uma democracia é tão sólida quanto mais o poder seja subdividido, fragmentado em uma gama de centros capazes de se controlarem reciprocamente. A multiplicação das fontes de informação é, portanto, funcional à própria democracia". Na mesma linha de pensamento está SILVA, Virgílio Afonso da. A constitucionalização do direito. Os direitos fundamentais nas relações entre particulares. São Paulo: Malheiros, 2005. p. 78. "Para ficar em um exemplo emblemático, é possível, a partir da liberdade de informação, que sempre foi entendida como uma liberdade pública, um direito a não ser obstado pela atividade estatal no exercício da plena busca pela informação - o que, como reflexo implica a exigência de outra abstaenção estatal: a vedação de censura - desenvolver uma outra dimensão desse direito: o direito a uma ação estatal, por exemplo, no sentido de garantir, via ação estatal, a pluralidade de fontes de informação e de coibir o monopólio nos meios de comunicação".

LANER, Vinicius Ferreira. Comunicação, desenvolvimento e democracia: uma análise crítica da mídia brasileira à luz do direito à informação e à liberdade de imprensa. Santa Cruz do Sul: Edunisc, 2004. p. 25. "Esses monopólios que dominam o mercado da indústria cultural constituem significativos entraves para democratização dos meios de comunicação. A concentração de meios de comunicação permitida no Brasil, com TVs, rádios, jornais e revistas na posse de um mesmo grupo ou mesmo centralizada em uma só pessoa, é uma força anti-democrática, anti-social e inconstitucional". Soma-se a posição contrária aos monopólios informativos, com abuso do poder privado a de UBILLOS, Juan María Bilbao. ¿En qué medida vinculan a los particulares los derechos fundamentales? In: SARLET, Ingo Wolfgang (Org.). Constituição, direitos fundamentais e direito privado. 3 ed. Porto Alegre: Livraria do Advogado, 2010. p. 221.

49 FISS, Owen. La ironía de la libertad de expresión. Barcelona: Gedisa, 1999. p. 74. "Algunos de quienes imaginaron un mayor papel para el Estado hablaron del <<poder monopólico >>. Invocaron estadísticas sobre el número de ciudades en América que no tienen periódicos o que sólo tienen uno - un número espantosamente alto de ciudades -, e hicieron referencia a la posición privilegiada de las tres grandes cadenas para captar la atención de la audiencia. Siempre encontré poco convincente esta manera de analizar la cuestión, no porque yo vislumbrara en el horizonte el cable o las nuevas tenologías de la información, sino porque quienes expresaron sus argumentos en términos de poder monopólico concebían el mercado de un modo demasiado estrecho. A efectos constitucionales, el mercado relevante es el informativo, el ámbito a partir del cual el público descubre el mundo que está más allá 
de su experiencia inmediata. El mercado relevante no puede ser definido para cada medio, sino que debe abarcar a los periódicos, la radio, la televisión, las revistas, los libros e incluso a las películas, en un todo unitario. En este mercado global, existen fuerzas dominantes 0 que ejrcen liderazgo y que dan forma a la opinión pública, pero no existe un monopolio".

A obra referida contém um estudo aprofundado sobre o assunto, sendo possível remeter uma passagem da obra apenas para demonstrar o caráter jurídico-crítico da abordagem de LANER, Vinicius Ferreira. Comunicação, desenvolvimento e democracia: uma análise crítica da mídia brasileira à luz do direito à informação e à liberdade de imprensa. Santa Cruz do Sul: Edunisc, 2004. p. 25. "Esses monopólios que dominam o mercado da indústria cultural constituem significativos entraves para democratização dos meios de comunicação. A concentração de meios de comunicação permitida no Brasil, com TVs, rádios, jornais e revistas na posse de um mesmo grupo ou mesmo centralizada em uma só pessoa, é uma força anti-democrática, anti-social e inconstitucional". Soma-se a isso o artigo seguinte que conta com pesquisa de dados atualizando, inclusive, a fundamentação do autor citado anteriormente VELOSO, Elizabeth Machado. A concentração da mídia e a liberdade de expressão na Constituição de 1988. In: ARAÚJJ, José Cordeiro. et al. Ensaios sobre impactos da constituição federal de 1988 na sociedade brasileiro. volume 1.Brasília: Câmara dos deputados, 2008. p. $103-136$.

PEREIRA, Guilherme Döring Cunha. Liberdade e responsabilidade dos meios de comunicação. São Paulo: Revista dos Tribunais. 2002. p. 28. "A afirmação de que cabe às empresas uma função social, de que elas têm uma função social inerente à atividade, não é mais algo realmente problemático. A idéia já ganhou foros de cidadania. Não seriam poucos os empresários que a endossariam, mesmo talvez sem saber exatamente o que vem implicado nela".

52 DONNINI, Oduvaldo; DONNINI, Rogério Ferraz. Imprensa livre, dano moral, dano à imagem e sua quantificação à luz do novo código civil. São Paulo: Método, 2002. p. 31. "Imprensa livre e influência direta do poder econômico e financeiro sempre foi uma relação perigosa. $O$ fato de grandes empresas utilizarem-se da imprensa para propagar uma certa imagem que algumas vezes está distante da realidade não é novidade. Para a proteção da sociedade existe legislação eficaz na defesa do consumidor. A grande preocupação é a nova fase dos meios de comunicação em que não apenas são comprados espaços publicitários na mídia falada, escrita e televisiva, mas adquiridos pelas grandes corporações os próprios veículos de comunicação. Nesse caso, investimentos grandiosos são realizados, que tendem a crescer ainda mais com a Internet na denominada indústria da imagem, e essa união entre imprensa e grande empresa (comercial ou industrial) revela-se perigosa, haja vista que interesses comerciais podem distanciar o fato verdadeiro da informação jornalística e, como conseqüência, aniquilar a função social da imprensa e seu compromisso com a veracidade da informação".

\section{REFERÊNCIAS}

ARAGÃO, Alexandre Santos de. Direito dos Serviços Públicos. Rio de Janeiro: Forense, 2007.

BARROSO, Luís Roberto. Fundamentos teóricos e filosóficos do novo direito constitucional brasileiro (pós-modernidade, teoria crítica e pós-positivismo). In: BARROSO, Luís Roberto (Org.). A nova interpretação constitucional: ponderação, direitos fundamentais e relações privadas. 2 ed. Rio de Janeiro: Renovar, 2006.

Colisão entre liberdade de expressão e direitos de personalidade. Revista latino-americana de estudos constitucionais. São Paulo: Del Rey. n. 5, janeiro - junho, 2005. 
BINENBOJM, Gustavo. A Constitucionalização do Direito Administrativo no Brasil: Um Inventário de Avanços e Retrocessos. In: BARROSO, Luís Roberto (Org.). A reconstrução democrática do direito público no Brasil. Rio de Janeiro: Renovar, 2007.

BONAVIDES, Paulo. Teoria do estado. 5 ed. São Paulo: Malheiros, 2004.

CANOTILHO, José Joaquim Gomes. Direito constitucional. 7 ed. Coimbra: Almedina, 2004.

CASTRO, Carlos Roberto Siqueira. A constituição aberta e os direitos fundamentais: ensaios sobre o constitucionalismo pós-moderno e comunitário. 2 ed. Rio de Janeiro: Forense, 2010.

CEZNE, Andrea Nárriman. O conceito de serviço público e as transformações do Estado contemporâneo. Revista de informação legislativa. Brasília. Número 167, 2005.

COMANDUCCI, Paolo. Uma defesa do positivismo metodológico. In: DIMOULIS, Dimitri; DUARTE, Écio Oto (Coords.). Teoria do direito neoconstitucional: superação ou reconstrução do positivismo jurídico? São Paulo: Método, 2008.

DONNINI, Oduvaldo; DONNINI, Rogério Ferraz. Imprensa livre, dano moral, dano à imagem e sua quantificação à luz do novo código civil. São Paulo: Método, 2002.

DI PIETRO, Maria Sylvia Zanella. Direito administrativo. 24 ed. São Paulo: Atlas, 2011.

DOWBOR, Ladislau. Democracia econômica: alternativas de gestão social. Petrópolis: Vozes, 2008.

FERRARI, Vincenzo. Democracia e informação no final do século XX. In: GUIMARẤES, César; JUNIOR, Chico (Org.). Informação e democracia. Rio de Janeiro: EdUERJ, 2000.

FISS, Owen. La ironía de la libertad de expresión. Barcelona: Gedisa, 1999.

GADAMER, Hans-Georg. Verdade e método l: traços fundamentais de uma hermenêutica filosófica. 7 ed. Petrópolis: Vozes, 2005.

GALUPPO, Marcelo Campos. Hermenêutica constitucional e pluralismo. In: SAMPAIO, José Adércio Leite; CRUZ, Álvaro Ricardo de Souza (Coord.). Hermenêutica e jurisdição constitucional. Belo Horizonte: Del Rey, 2001.

GRECO, Marco Aurélio. Aspectos da concessão de serviço público. Revista de direito público. São Paulo: Revista dos Tribunais. Volume 21. 
GRONDIN, Jean. Introdução à hermenêutica filosófica. São Leopoldo: Unisinos, 1999.

GUERRA, Sidney Cesar Silva. A liberdade de imprensa e o direito à imagem. 2. ed. Rio de Janeiro: Renovar, 2004.

HÄBERLE, Peter. Os problemas da verdade no estado constitucional. Porto Alegre: Sergio Fabris, 2008.

HABERMAS, Jürgen. A inclusão do outro - estudos de teoria política. 2 ed. São Paulo: Edições Loyola, 2004.

- Consciência moral e agir comunicativo. Rio de Janeiro: Tempo Brasileiro, 1989.

. Direito e democracia: entre facticidade e validade I. Rio de Janeiro: Tempo Brasileiro, 1997.

LANER, Vinicius Ferreira. Comunicação, desenvolvimento e democracia: uma análise crítica da mídia brasileira à luz do direito à informação e à liberdade de imprensa. Santa Cruz do Sul: Edunisc, 2004.

LEAL, Rogério Gesta. Esfera Pública e Participação social: possíveis dimensões jurídico-políticas dos direitos civis de participação social no âmbito da gestão dos interesses públicos no Brasil. In: LEAL, Rogério Gesta. Administração pública compartida no Brasil e na Itália: reflexões preliminares. Santa Cruz do Sul: Edunisc, 2008.

LIMBERGER, Têmis. $O$ direito à intimidade na era da informação: a necessidade de proteção dos dados pessoais. Porto Alegre: Livraria do Advogado, 2007.

LUCAS, Doglas Cesar. Hermenêutica filosófica e os limites do acontecer do direito numa cultura jurídica aprisionada pelo "procedimentalismo metodológico". In: LUCAS, Doglas Cesar; SPAREMBERGER, Raquel Fabiana Lopes. Olhares hermenêuticos sobre o direito: em busca de sentido para os caminhos do jurista. 2 ed. ljuí: Unijuí, 2007.

MAGALHÃES FILHO, Glauco Barreira. Hermenêutica e unidade axiológica da constituição. 2 ed. Belo Horizonte: Mandamentos, 2002.

MEIRELLES, Hely Lopes. Direito administrativo brasileiro. 36 ed. São Paulo: Malheiros, 2010.

MIRAGEM, Bruno. Liberdade de imprensa e proteção da personalidade no direito brasileiro: perspectiva atual e visão de futuro. Revista trimestral de direito civil. Rio de Janeiro: Padma. v. 40, outubro - dezembro, 2009.

OLIVEIRA, Manfredo Araújo de. Reviravolta lingüístico-pragmática na filosofia contemporânea. São Paulo: Edições Loyola, 2001. 
PEREIRA, Guilherme Döring Cunha. Liberdade e responsabilidade dos meios de comunicação. São Paulo: Revista dos Tribunais, 2002.

PEREZ LUÑO, Antonio Enrique. Derechos humanos, estado de derecho y constitución. 9 ed. Madrid: Tecnos, 2005.

ROHDEN, Luiz. Hermenêutica filosófica. São Leopoldo: Unisinos, 2003.

RODRIGUEZ, Javier Llobet. Derechos humanos y justicia penal. Heredia: Poder Judicial, Depto. De Artes Gráficas, 2007.

SABAU, José Ramón Pólo. Libertad de expresión y derecho de acesso a los médios de comunicación. Madrid: CEPC, 2002.

SACHS, Ignacy. Caminhos para o desenvolvimento sustentável. 3 ed. Rio de Janeiro: Garamond, 2008.

SARLET, Ingo Wolfgang. Dignidade da pessoa humana e direitos fundamentais na constituição federal de 1988. 5 ed. Porto Alegre: Livraria do Advogado, 2008.

SARMENTO, Daniel. Direitos Fundamentais e relações privadas. 2 ed. Rio de Janeiro: Lúmen Juris, 2010.

SCHMITT, Rosane Heineck. Direito à informação - liberdade de imprensa $x$ direito à privacidade. In: SARLET, Ingo Wolfgang (Org.). A constituição concretizada: construindo pontes com o público e o privado. Porto Alegre: Livraria do Advogado, 2000.

SILVA, Virgílio Afonso da. A constitucionalização do direito. Os direitos fundamentais nas relações entre particulares. São Paulo: Malheiros, 2005.

SOUZA, Sérgio Ricardo de. Controle judicial dos limites constitucionais à liberdade de imprensa. Rio de Janeiro: Lumen Juris, 2008.

STRECK, Lenio Luiz. Hermenêutica jurídica $e(m)$ crise: uma exploração hermenêutica da construção do direito. 3 ed. Porto Alegre: Livraria do Advogado, 2001.

. A revelação das "obviedades" do sentido comum e o sentido (in)comum das "obviedades" reveladas. In: CAMPUZANO, et al. O poder das metáforas: homenagem aos 35 anos de docência de Luis Alberto Warat. Porto Alegre: Livraria do Advogado, 1998.

TEPEDINO, Gustavo. Normas constitucionais e direito civil na construção unitária do ordenamento. SOUZA NETO, Cláudio Pereira de; SARMENTO, Daniel (Coord.). A constitucionalização do direito: fundamentos teóricos e aplicações específicas. Rio de Janeiro: Lumen Júris, 2007. 
TERRA, Eduardo Héguy. La responsabilidad de los medios de comunicación. Montevideo: Fundación Fontana Minelli, 2001.

UBILLOS, Juan María Bilbao. ¿En qué medida vinculan a los particulares los derechos fundamentales? In: SARLET, Ingo Wolfgang (Org.). Constituição, direitos fundamentais e direito privado. 3 ed. Porto Alegre: Livraria do Advogado, 2010.

VELOSO, Elizabeth Machado. A concentração da mídia e a liberdade de expressão na Constituição de 1988. In: ARAÚJO, José Cordeiro. et al. Ensaios sobre impactos da constituição federal de 1988 na sociedade brasileiro. volume 1.Brasília: Câmara dos deputados, 2008.

Recebido para publicação: 07/09/2011

Aceito para publicação: 13/12/2011 